\title{
Lung involvement in the multisystem syndrome CHARGE association
}

\author{
R. Sporik, R. Dinwiddie, C. Wallis
}

\begin{abstract}
Lung involvement in the multisystem syndrome CHARGE association. R. Sporik, $R$. Dinwiddie, C. Wallis. @ERS Journals Ltd 1997.

ABSTRACT: The CHARGE association is a multisystem syndrome, with a wide range of phenotypic expression, causing mortality, especially in childhood.

We performed a hospital audit, in order to quantify the pulmonary implications, in 28 boys and 19 girls aged $0.02-23$ yrs, with a definite diagnosis of CHARGE.

A review of the records of these children with CHARGE association revealed that aspiration was common during infancy, as a result of inco-ordination of swallowing and gastro-oesophageal reflux. Aspiration was suspected in 22 of the 47 cases $(47 \%)$, recurrent chest infections occurred in 22 cases $(47 \%)$, and lung involvement contributed to 7 out of 17 deaths $(41 \%)$.

We conclude that respiratory morbidity and mortality is common in CHARGE, and decreases with age. Early diagnosis and treatment affords the best prognosis. Eur Respir J 1997; 10: 1354-1355.
\end{abstract}

The Respiratory Unit, Great Ormond Street Hospital for Children, NHS Trust, London, UK.

Correspondence: C. Wallis

Respiratory Unit

Great Ormond Street Hospital for Children NHS Trust

London WC1N 3JH

UK

Keywords: CHARGE association multiple abnormalities respiratory tract disease

Received: September 201996

Accepted after revision February 201997
CHARGE is an acronym referring to an association of: coloboma; heart defects; atresia (choanal); retardation of growth and neurodevelopment; genitourinary anomalies; and ear abnormalities, including deafness. There is variable expression of these somatic manifestations, but the cardinal features of either coloboma or choanal atresia are required, by definition $[1,2]$. Whilst respiratory problems are not represented in the CHARGE acronym, they can cause considerable morbidity and mortality, especially during infancy. We have undertaken an audit to quantify the pulmonary implications of the CHARGE association.

\section{Methods}

The hospital records of children with a diagnosis or features of the CHARGE association seen in this hospital were reviewed. Those children with a certain diagnosis (coloboma or choanal atresia and an additional feature) and no chromosomal abnormalities were included in further analysis. As the CHARGE association has not yet been allocated an International Classification of Childhood Disease (ICCD) code, and as there is no "in-house" coding, comprehensively identifying cases was difficult. A list of children from previous surveys was used as a core index $[3,4]$.

\section{Results}

Forty seven children ( 28 boys and 19 girls), with a definite diagnosis of CHARGE were identified. The median age at review was 4.7 yrs (range 0.02-23 yrs). Structural abnormalities of the upper respiratory tract were common: 31 nasal abnormalities; 12 palatal defects; 5 laryngeal anomalies. Structural abnormalities to the lower respiratory tract were less common: 5 tracheooesphageal fistulae; 1 tracheal stenosis; 1 right main bronchus stenosis; and 1 hypoplastic lung.
Functional abnormalities of swallowing were extremely common. Feeding difficulties were recorded in 37 children, with 12 requiring nasogastric feeding and 3 nasojejunal feeding during early infancy. Inco-ordination of swallowing was documented in 26 cases $(55 \%)$

Aspiration was suspected clinically in $22(47 \%)$ children, who suffered with recurrent chest infections. Gastrooesophageal reflux was demonstrated either by $\mathrm{pH}$ or barium studies in 18 of these 22 children. The children with documented gastro-oesophageal reflux, aspiration and recurrent chest infections were a highly congruous group. The approach to their management and the outcomes are summarized in figure 1. Four children demonstrated inco-ordinate swallowing as a cause for recurrent chest infection, without significant gastro-oesophageal reflux. Gastrostomy feeding did not fully resolve the aspiration pneumonia: one child died; two patients required a tracheostomy to protect the lungs and aid bronchial toilet; and one was lost to follow-up.

Eighteen of the 22 children showed gastro-oesophageal reflux as a contributory factor to their recurrent pneumonia. Medical therapy using a combination of prokinetic and antacid therapy failed in 17 of this group: two died, and 15 required a Nissen's fundoplication with gastrostomy feeding. Nonwithstanding this surgery, four died following aspiration pneumonia and five continued to aspirate, necessitating tracheostomy.

The mortality in this cohort of children with CHARGE syndrome was high, with 17 (36\%) deaths. Analysis of those children who died (table 1) revealed a pattern of very early deaths due to severe cardiac abnormalities, followed by those attributed to chest problems (41\%). The cause of death was confirmed by postmortem examination in only four children. Seven children died despite anti-reflux medication or surgical intervention. Of the total survivors, three required supplemental oxygen (mean age 1.4 yrs) but $21(70 \%)$ reported having no respiratory problems. 


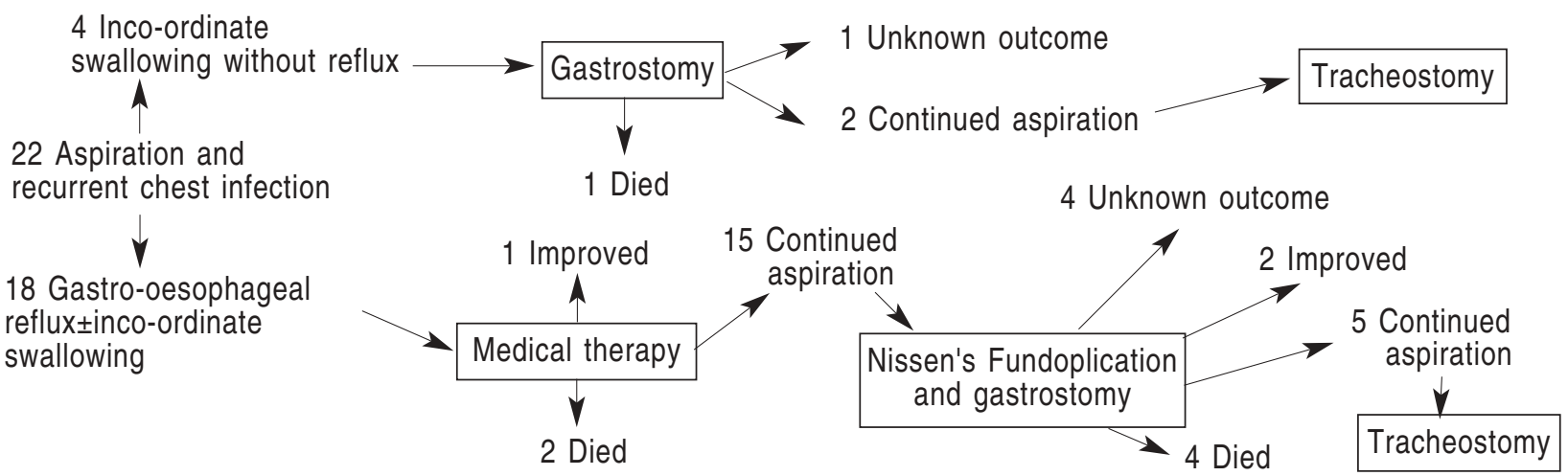

Fig. 1. - Management and outcome of 22 children with CHARGE syndrome and recurrent aspiration pneumonia. CHARGE: acronym referring to association of coloboma; heart defects; atresia (choanal); retardation of growth and neurodevelopment; genitourinary anomalies; and ear abnormalities, including deafness.

Table 1. - Cause of death in 17 children with CHARGE association

\begin{tabular}{|c|c|}
\hline \multicolumn{2}{|c|}{$\begin{array}{l}\text { Age } \\
\text { months }\end{array}$} \\
\hline$<1$ & PA, VSD, PDA, treatment declined \\
\hline$<1$ & $\begin{array}{l}\text { AVSD, aortic coarctation, PDA, intraoperative death } \\
\text { during repair, PM }\end{array}$ \\
\hline 1 & $\begin{array}{l}\text { Hypoplastic right heart, PA, TOF, cardiac failure, } \\
\text { bronchopneumonia }\end{array}$ \\
\hline 2 & Large VSD, interrupted aorta, PDA, treatment declined \\
\hline 4 & $\begin{array}{l}\text { Aspiration, RLL bronchopneumonia, Nissen's } \\
\text { fundoplication with gastrostomy }\end{array}$ \\
\hline 4 & Same day postanaesthetic for palate repair, TOF, PM \\
\hline 4 & Sudden infant death \\
\hline 4 & Chest infection, anti-reflux medication \\
\hline 5 & $\begin{array}{l}\text { Found dead in cot, gastrostomy, PM: } \\
\text { bronchopneumonia consistent with aspiration }\end{array}$ \\
\hline 6 & $\begin{array}{l}\text { Hypoplastic left heart, AVSD, PDA, aspiration, TOF, } \\
\text { anti-reflux medication }\end{array}$ \\
\hline 6 & Aspiration, Nissen's fundoplication with gastrostomy \\
\hline 8 & Aspiration of vomit \\
\hline 14 & $\begin{array}{l}\text { ? Septicaemia post-UTI, bilateral reflux, Nissen's } \\
\text { fundoplication with gastrostomy, anti-reflux medication }\end{array}$ \\
\hline 16 & Post-Senning procedure, septicaemia, DIC \\
\hline 40 & Cardiomyopathy, Fallot's tetralogy \\
\hline 58 & $\begin{array}{l}\text { VSD, pulmonary atresia, TOF, Nissen's fundo- } \\
\text { plication with gastrostomy, anti-reflux medication }\end{array}$ \\
\hline 96 & $\begin{array}{l}\text { Repaired Fallot's tetralogy, PM: myocardial ischaemia, } \\
\text { chest infection }\end{array}$ \\
\hline
\end{tabular}

AVSD: atrioventricular defect; DIC: disseminated intravascular coagulopathy; PA: pulmonary atresia; PDA: patent ductus arteriosus; PM: postmortem, TOF: tracheo-oesophageal fistula; UTI: urinary tract infection; VSD: ventricular septal defect; RLL: right lower lung. For further definitions see legend to figure 1.

\section{Discussion}

The CHARGE association is a multisystem disorder with a wide range of phenotypic expression. The effects of this condition on the lungs have not previously been highlighted as a significant feature. Our review of 47 patients indicated that respiratory morbidity and mortality were common. The lungs could be affected in two ways. Firstly, by a primary structural malformation, although this was uncommon. Secondly, and far more common, was the effect of aspiration. Inco-ordination of swallowing resulted in aspiration both of saliva and oral feeds. In addition, gastro-oesophageal reflux could result in the aspiration of gastric contents. These factors caused long-term lung damage, recurrent chest infections, and a number of deaths. The death rate was high (36\%) in this group of complicated patients seen at a tertiary referral centre. However, within the limitations of such a study, a large proportion of children with CHARGE association had respiratory sequelae.

Functional abnormalities of swallowing and gastrooesophageal reflux are common in children with hypotonia and neurocognitive defects. It is unclear whether the CHARGE association in itself or its associated neurological deficits cause these lung problems. However, early identification of these underlying motility problems, combined with appropriate medical and surgical treatment, is necessary to protect the lungs in infancy and afford the best chance of survival.

Should medical therapy fail to control gastro-oesophageal reflux, then a Nissen's fundoplication and gastrostomy feeding is indicated, and tracheostomy should also be considered, not only to relieve upper airway obstruction but also to ensure optimal bronchial clearance. The morbidity and mortality from lung involvement decreased in the older children, suggesting either that the most severely affected died young or that the functional abnormalities improved with age.

Acknowledgement: The authors thank R. Wyse for help in locating the cases.

\section{References}

1. Hall BD. Choanal atresia and association multiple anomalies. J Pediatr 1979; 95: 395-398.

2. Pagon RA, Graham JM Jr, Zonan J, Young SL. Coloboma, congenital heart disease, and choanal atresia with multiple anomalies: CHARGE association J Pediatr 1981; 99: 223-227.

3. Blake KD, Russell-Eggitt IM, Morgan DW, Ratcliffe JM, Wyse RKH. Who's in CHARGE? Multidisciplinary approach to the management of patients with CHARGE association. Arch Dis Child 1990; 65: 217-223.

4. Morgan D, Bailey M, Phelps P, Bellman S, Grace A, Wyse R. Ear, nose, throat abnormalities in the CHARGE association. Arch Otolaryngol 1993; 119: 49-54. 